\title{
Performing Under Uncertainty: Contextualized Engagement in Wildland Firefighting
}

\section{Michelle A. Barton*, Kathleen M. Sutcliffe**, Timothy J. Vogus*** and Theodore DeWitt****}

*Organizational Behavior, Boston University School of Management, 595 Commonwealth Ave, Boston, MA 02215, USA. E-mail: mbarton@bu.edu

**Johns Hopkins University, 100 International Drive, Baltimore, MD 21202, USA. E-mail: ksutcliffe@jhu.edu

***Vanderbilt Owen Graduate School of Management, 40121 st Avenue South, Nashville, TN 37203-2422,

USA. E-mail: timothy.vogus@owen.vanderbilt.edu

****University of Michigan Ross School of Business, 701 Tappan, Ann Arbor, MI 48109-1234, USA. E-mail:

teddydew@umich.edu

In this paper, we propose that performance under uncertainty and ambiguity is enabled by a two-pronged set of practices enacted by leaders and frontline workers. These contextualized practices fuel performance by enabling teams and organizations to both discern, interpret and make sense of important discrepancies as situations unfold (what we refer to as anomalizing), and to develop a richer understanding of a situation (what we call proactive leader sensemaking). Together, these situation-specific practices contextualize engagement and promote capabilities to contingently tailor actions to unfolding conditions. We test our hypotheses using data gathered from a sample of wildland firefighters and find strong support for our theorizing. We also identify a set of additional group and situational conditions that provide a more nuanced understanding of factors that contribute to reliable performance under dynamic uncertainty. Together, the findings provide quantitative evidence for the micro-foundations of effective performance in uncertain contexts.

\section{Introduction}

A Imost all theories of organization highlight the necessity for organizations to adapt in the face of uncertainty (e.g., Burns \& Stalker, 1961; Perrow, 1967; Thompson, 1967). Uncertainty, often experienced as a sense of doubt or inadequate understanding that arises from the ambiguity or equivocality of inputs (Lipshitz \& Strauss, 1997), can confuse or delay actions. In high-risk settings, this can have large and deadly consequences.

Uncertainty shapes the extent to which work behaviours and task requirements can be formalized rather than left to emerge through adaptive and proactive behaviours. In certain contexts, work activities can be accomplished through the use of systematic, routine, rational, bureaucratic procedures, whereas uncertain conditions require more flexible, experimental and improvisational approaches. Bureaucratic routines can be both efficient and effective under conditions of relative certainty. Uncertainty, however, requires alternative, interpersonal, high bandwidth coordinating mechanisms (Gittell, 2002). Moreover, when contextual uncertainty is exceptionally high and one cannot imagine or anticipate action interdependencies and contingencies, organizations and their members may face uncertainty not only about future realities, but also 
uncertainty about the current state of events. Dynamic and complex situations often create a state of equivocality or ambiguity - in which data are unclear and subject to multiple interpretations (Weick, 2001). The uncertainty challenge in such environments is one of sensemaking. That is, organizations need to develop interactive practices and processes that enable ways of thinking and acting to make sense of the ambiguity and facilitate swift, coordinated action. In this paper, we explore the dual process of how leaders help shape the context and model how to make sense in such circumstances through proactive sensemaking as well as how those on the frontline actually attend to weak signals through processes of anomalizing (Weick \& Sutcliffe, 2006).

Our theorizing builds from research exploring the dynamics of high reliability organizing (Roberts, 1990; Vogus \& Sutcliffe, 2007a; Weick, Sutcliffe, \& Obstfeld, 1999) as well as studies of extreme actions teams (e.g., Klein, Ziegert, Knight, \& Xiao, 2006) and fast response organizations (Faraj \& Xiao, 2006). High reliability organizations (HROs) strive to continuously manage ambiguity, complexity and fluctuations by sustaining attention or watchfulness. HROs are adaptive organizational forms for uncertain and ambiguous environments (Weick et al., 1999, 82). They have unique capabilities to dynamically organize, which enables organizational actors both to make sense of uncertainty and ambiguity as events unfold and to flexibly respond.

Research over the past decade (see Vogus et al., 2007a; Vogus \& Sutcliffe, 2007b; Vogus \& Welbourne, 2003; Roe \& Schulman, 2008; Madsen, Desai, Roberts, \& Wong, 2006; Roberts, Madsen, Desai, \& Van Stralen, 2005) has examined the broad organizing principles through which reliable performance in uncertain and ambiguous contexts is achieved. But, much less is known about the micro-level behaviours that underlie dynamic and adaptive organizing. Our goal in this paper is to remedy this gap and particularly attend to micro-level adaptive and proactive behaviours that facilitate coordination and reliable performance when uncertainty is high. We propose that the foundation of dynamic and adaptive organizing (which ultimately results in better performance) stems from the contextualized engagement of actors at multiple organizational levels (Faraj et al., 2006). Specifically, we hypothesize that effective performance is enabled when frontline employees actively strive to capture discriminatory contextual details and build coherent interpretations of them (anomalizing), and, when leaders proactively exhibit behaviours aimed at comprehensive and continuous sensemaking (proactive leader sensemaking). We test our hypotheses in the context of wildland firefighting, a context in which surprises can be deadly, and making adjustments to ongoing action before they can turn into a tragic flaw (Perin, 2005) is critical.

\section{Conceptual framework and hypotheses}

\subsection{Foundations of high performance under uncertainty}

Performance in uncertain contexts is a situationspecific accomplishment that involves managing contradictions and interruptions (Barton \& Sutcliffe, 2009; Christianson, Farkas, Sutcliffe, \& Weick, 2009; Weick, 2011; Weick et al., 1999). Organizations that strive for highly reliable performance provide a template for understanding how this is accomplished. HROs face special problems of learning and acting in the face of ambiguity because of risky technologies or work processes that are not fully comprehended and continuous exposure to dynamic contingencies. The patterns of organizing visible in HROs, serve to 'induce a rich awareness of discriminatory detail and a capacity for action' (Weick et al., 1999, p. 88). Mindful infrastructures (Weick etal., 1999) guard against misspecifying, misestimating and misunderstanding things (Schulman, 2004; Vogus et al., 2007b). That is, by increasing an organization-wide sense of vulnerability, mindful infrastructures mitigate production pressures that can otherwise exacerbate the tendency to normalize or overlook discrepancies signalling that things are unraveling. Thus, HROs can quickly discover, make sense of and correct minor perturbations that can build and cause major disruptions.

There is growing evidence of the salutary effects of these broad patterns of mindful organizing on reliable performance (e.g., Bigley \& Roberts, 2001; Madsen et al., 2006; Rerup, 2009; Roberts et al., 2005; Vogus et al., 2007a, 2007b). For example, Vogus et al. (2007a, 2007b) studied the relationship between mindful organizing practices and the commission of medication errors in hospital nursing units finding that fewer medication errors occurred over the subsequent 6 months on units with higher levels of mindful organizing. These studies provide a strong foundation, but lack a detailed examination of the micro-level behaviours by which leaders and frontline employees process organizational conditions under uncertainty. We develop how leaders and frontline employees do this in the following section.

\subsection{Processes of contextualized engagement}

Managing uncertainty and ambiguity requires attention and alertness, but it also requires discernment, understanding what emerging cues signify, interpreting changes in those cues and determining how behaviours can be adjusted in response. Discernment, in part, means that people appreciate the meaning or significance of data elements (Klein, Pliske, Crandall, \& Woods, 2005, p. 20). But, the meaning of data changes as context changes, which means that 'important signals' 
change as the details of the current situation change (Sutcliffe \& Weick, 2008).

Organizations that operate effectively under uncertainty balance these adjustments by simultaneously engaging different parts of the system (Klein et al., 2006; Weick, 2011). By dynamically blending actions of supervisors and frontline staff, HROs continuously adjust to create a more coherent understanding of what they face and a more composite response (Barton et al., 2009; Roe et al., 2008; Weick, 2011). This requires contextualized behaviours at both levels. The frontline has access to concrete situational details, what Baron and Misovich (1999) call knowledge by acquaintance, whereas leadership has knowledge by description, which fuels broader understanding and action options (Weick, 2011, p. 23). Description is essential for sensemaking and organizing, but acquaintance is critical for successfully navigating ambiguity and dynamism. The implication is that to manage and respond to highly dynamic and uncertain contexts, organizations must have processes in place that interrupt the momentum of ongoing events, thereby providing space and means for renewed awareness and sensemaking (Barton et al., 2009). Such processes presumably enable organizations to interrupt current frames and to notice, interpret and coordinate around new or different conditions as they unfold. In the following paragraphs, we develop hypotheses regarding both aspects of this dual process frontline employee anomalizing and proactive leader sensemaking.

\subsubsection{Anomalizing}

Previous research suggests that untoward events and crises are often foreshadowed by small discrepancies and anomalies that signal that events are not unfolding as planned (e.g., Turner, 1976). Such anomalies are critical signals that the system is breaking down (Rerup, 2009; Sutcliffe \& Christianson, 2011; Weick \& Sutcliffe, 2007). Yet, particularly, when there are performance and production pressures, there is a tendency to ignore or normalize such signals (Starbuck \& Farjoun, 2005; Vaughan, 1996). Consequently, to perform effectively under uncertainty requires organizational members to be vigilant to anomalies and treat them as critical indicators of potential, emergent problems, rather than as normal. We use the term anomalizing to mean taking proactive steps to become alert to discrepancies, to understand them more completely, and to be less encumbered by history (Sutcliffe et al., 2011; Weick et al., 2007). In other words, anomalizing involves both noticing discrepancies and perturbations as well as actively working to understand them without simplifying them into familiar categories. The more people hold on to differences, nuances, discrepancies and outliers, the more slowly they normalize the details and the more nuanced and fine-grained an understanding they can create. More detailed understanding of anomalies also enables discrepant events to be acted upon more precisely and swiftly, before becoming unmanageable.

Anomalizing, however, is not just a passive process. Anomalies can be created as well as noticed. For example, Barton et al. (2009) found that frontline firefighters created anomalies by collecting diverse perspectives on a fire in two ways. First, by taking a different perspective (e.g., by moving from the ground to elevation), firefighters deliberately created more than one interpretation of ongoing events - a kind of discrepancy that prompted a review of current assumptions and actions. Second, firefighters also sought out different perspectives by engaging with others who had different expertise or levels of experience. These actions contribute to more effective performance under uncertainty by creating a more accurate and complete picture of unfolding conditions. This consistent and disciplined revising of one's understanding means that surprises like those that overwhelmed firefighters at Mann Gulch (Weick, 1993), South Canyon (Weick, 1995) and Cerro Grande (Weick et al., 2007) are less likely to occur and, if they do, be managed more swiftly. Therefore, we hypothesize that when frontline employees (e.g., firefighters) in uncertain contexts avoid the tendency to normalize by deliberately seeking, encouraging, and welcoming the noticing and discernment of anomalies, they will perform better.

Hypothesis 1:Anomalizing will be positively associated with organizational performance.

\subsubsection{Proactive leader sensemaking}

Anomalizing is an active approach to managing uncertain contexts. As such, it can be facilitated or hindered by other organizational factors. In particular, leaders play a critical role in creating and maintaining a context for anomalizing. Through their behaviour, leaders communicate to group members fundamental assumptions about the situation and the appropriate processes for managing it. Specifically, leaders are in a position to frame the situation as uncertain and dynamic, and thus worthy of greater vigilance and exploration. Their behaviour also models the accepted approaches to managing such situations. Thus, when leaders proactively inquire and seek to make sense of potential problems, differences of perspective or other discrepancies, they send two messages. First, by proactively directing attention to sensemaking leaders signal that there is no one right answer or perspective on the situation. By encouraging divergent thinking, the leader presents the situation as uncertain - as something still to be understood.

Second, by seeking out diverse perspectives and encouraging people to bring up problems or different viewpoints, leaders model how such ambiguity is to be managed. By encouraging group members to share with 
the leader (not just among themselves), the leader not only signals the importance of voice, but also forces $\mathrm{him} /$ herself to be constantly faced with the question 'what's the story now?' Research shows that frontline employees often notice anomalies and discrepancies and have divergent perspectives, but they often fail to voice their concerns to others (e.g., Barton et al., 2009; Blatt, Christianson, Sutcliffe, \& Rosenthal, 2006; Weick et al., 2007). Voice by itself is important in uncertain environments particularly for surfacing discrepant cues. But, a secondary benefit of 'voice' is that it triggers the integration of information and renewed sensemaking in leaders. Consequently, it enables more effective action taking. If group members only tell each other and it never gets to leaders and other decision makers, these people in power are unable to use the data in their own sensemaking. For example, Weick (2011, p. 22) describes how Paul Gleason, a renowned fire superintendent, privileged sensemaking practices over decision-making practices. As Gleason explained, he wanted to create a dynamic, flexible context to enable all to be able to cope with a changing fire environment (Weick, 2011, p. 22). This line of thinking leads us to hypothesize that proactive leader sensemaking in uncertain contexts is positively associated with performance.

Hypothesis 2: Proactive leader sensemaking will be positively associated with performance.

\subsection{Contextual and organizational factors}

Within an inherently uncertain context, like wildland firefighting, organizational actors may experience additional sources of uncertainty that particularly affect the complexity and ambiguity of unfolding events and might influence their behaviour and performance. Three sources of such uncertainty are noteworthy: goal clarity (Locke, Saari, Shaw, \& Latham, 1981), group familiarity (e.g., Goodman \& Leyden, 1991), and task interdependence (Murphy \& Jackson, 1999). Although we consider these sources of uncertainty as boundary conditions and include them as control variables, we theorize about them to build a more nuanced understanding of factors that affect the management of uncertainty and unfolding events.

Even when the environment overall is uncertain, in any given situation organizations vary with respect to the clarity of their immediate goals. Goal clarity is critical to coordinating in times of uncertainty because goals direct and focus attention and action (Locke et al., 1981). Moreover, goals are a target against which to measure and make sense of current performance. In the absence of clear goals, organizational actors may struggle to analyse progress with the result that coordination and predictability likely suffer.

Individuals in general and wildland firefighters specifically have to work together to accomplish the goals of the organization. The effectiveness of these collectives depends, in large part, on their ability to coordinate and leverage the knowledge and expertise of their members (Faraj \& Sproull, 2000; Rulke \& Galaskiewicz, 2000). When group members know one another well, they are better able to anticipate each other's actions, communicate the nature of the task, and make use of the skills and expertise on their team. However, when group members do not know one another, uncertainty increases as the unfamiliarity introduces an additional source of ambiguity and unpredictability.

Finally, task interdependence - the extent to which individuals or units depend on each other to accomplish their tasks - varies according to the structure of the organization and the nature of the task (Thompson, 1967). Task interdependence affects performance under uncertainty by adding complexity to unfolding events, increasing the need for coordination and creating additional uncertainty as a result.

\section{Method}

\subsection{Research context}

We studied wildland firefighting - an uncertain context in which attention to discriminatory detail is essential to performance. Wildland firefighting involves a range of fire management efforts, including extinguishing unwanted wildfires (suppression), purposefully setting controlled fires to burn off hazardous fuels such as excess undergrowth (prescribed fires) and overseeing, but not interfering with naturally occurring wildfires, also as a means of reducing hazardous fuels (wildland fire use). These three types of efforts are overseen by a team of individuals structured within a formal hierarchy, called an incident command system.

An incident commander (IC; or a 'Burn Boss' in the case of prescribed fires) generally leads the incident command team and has full responsibility for managing the fire response. In larger fires, individuals responsible for planning, operations, finance, logistics and safety assist the IC, whereas in smaller fires, the IC handles all of these functions. In addition, there are unit-level leaders responsible for a specific group, such as an engine crew or ground crew. These unit leaders report to the head of operations (and ultimately to the IC). In larger fires, additional levels of oversight may be added. For example, crew bosses will report to division supervisors who in turn report to the head of operations.

Wildland firefighting is a highly uncertain context, as fires move rapidly and unpredictably, their behaviour and intensity varying with rapidly changing wind, weather and fuel conditions. In addition, a huge variety of human resources (including fire analysts, smoke jumpers, frontline fighters, safety and public relations officers) and physical resources (from shovels to aircraft) must be distributed, coordinated and effectively 
utilized. In addition to environmental uncertainty, teams and units experience varying amounts of goal clarity and familiarity (e.g., units comprised of individuals from different states with little to no knowledge of one another's capabilities).

\subsection{Data collection and sample}

The primary data used to test our hypotheses were gathered from a sample of wildland firefighters who were involved in US fire management 'on the ground'. The management of fire involves many people in a wide variety of organizations, a large number of whom provide critical infrastructure, planning and support but do not physically become involved in a fire incident on the ground. Much of the work of fire management occurs long before any flames are seen. However, since we were interested in the ongoing action of managing a fire on the ground under uncertain and changing conditions, we chose to focus exclusively on the activities of people who are called upon to physically manage or suppress a fire. The survey population included permanent seasonal and full-time employees filling primary fire positions (including fire, fuels, dispatch and fire aviation) in the USDA Forest Service (USFS) and US DOI Bureau of Land Management (BLM) and National Park Service (NPS). Because sampling was necessarily conducted using day job positions, but the research questions relate to incident positions, we defined our initial sampling frame by agency and day job, then coded responses for analysis based on the incident position respondents provided as part of the survey.

\subsection{Procedure}

We collected the data using a telephone survey. We drew a stratified random sample of administrative units from complete lists of USFS Forests, BLM State Offices and NPS Parks with fire programs to reflect the relative proportions of federal fire personnel. Proportions were based on a target of 700 surveys: 400 USFS employee respondents (57\%), 200 BLM respondents $(29 \%)$ and 100 NPS respondents (14\%). Major units (such as parks, national forests, state offices) were randomly selected, and where multiple subunits occurred for a given major unit (such as multiple ranger districts on a national forest), these were again randomly sampled and complete telephone lists of permanent fire employees (fulltime and seasonal) were obtained for the head office and selected local unit. Individual respondents were randomly selected from these lists to reflect the relative proportions of fire personnel in each administrative level: $57 \%$ of surveys from ground-level, $29 \%$ from midlevel and $14 \%$ from upper level positions.

The survey was administered by telephone by the University of Montana's Bureau of Business and Eco- nomic Research. After asking for basic demographic data, we asked respondents to think back to their most recent fire event. The dates of these events ranged from the day of the interview to 6 months earlier; most occurred within 2 or 3 months of the interview. Respondents provided basic data about the fire event, the size of the fire and the location. They were then asked to respond to a series of questions about their experiences on the fire, using Likert-type scales. For questions relating to a respondent's perceptions about his or her work crew, respondents were asked to 'consider the people with whom you interacted most frequently (e.g., your unit)' and to answer the questions as they related to this particular group.

We obtained usable data from 518 out of 700 respondents, with a response rate of $74 \%$. Thirty-seven per cent of respondents worked for the US Park Service, $24 \%$ worked for the BLM and $39 \%$ worked for the USFS. Seventy-nine per cent of respondents were male, the average age was 41 years (ranging between 22 and 65) and average experience in fire management was 16 years (ranging from 1 to 45 ).

\subsection{Analyses}

We created indices to assess the key variables. Measures of all variables were constructed by taking the average of survey items rated on a 5-point Likert-type scale. Performance was measured using four items (Cronbach's alpha $=.62$, sample item 'Overall, how well did you feel this fire was managed'). It is important to note that respondents acted as key informants rating overall performance on the fire, not their own performance on the fire (Glick, Huber, Miller, Doty, \& Sutcliffe, 1990). Proactive leader sensemaking was measured using eight items (Cronbach's alpha $=.89$, sample item 'My boss encouraged people to bring up potential problems'). Anomalizing was measured using five items (Cronbach's alpha $=.78$, sample item 'We actively looked for instances of small things going wrong to try to learn what was happening'). Please see Appendix for full list of proactive leader sensemaking and anomalizing items. Given that these measures as well as some of our control variables were newly developed for this study, we conducted exploratory factor analysis with oblique rotation and found that all items cleanly loaded onto the appropriate factor with no crossloadings higher than .3 .

In our analyses, we also controlled for the internal sources of uncertainty described earlier as well as individual, crew and fire characteristics likely to influence performance. We controlled for the survey respondent's years of experience in fire management as well as their gender $(1=$ male, $0=$ female). Because of the skewed nature of this measure, we took the natural logarithm. We controlled for the familiarity among 
members of the firefighting crew using two survey items (Cronbach's alpha $=.84$, sample item 'How well did you know the skills and abilities of this group?'), used three items to measure the clarity of their goals (Cronbach's alpha $=.78$, sample item 'Our mission and objectives for each day were clear throughout the day'), and three items to assess their level of task interdependence (Cronbach's alpha $=.68$, sample item 'The way each person performed their work had a significant impact on how others were able to perform their work'). We also used a series of dummy variables to control for the survey respondent's role (categories included 'command and general staff, 'ground supervisor', 'ground individual' and 'support'. 'Command and general' staff was the omitted category) and the fire type (e.g., wildland, prescribed or suppression) with wildland as the omitted category.

\section{Results}

Table 1 displays descriptive statistics as well as correlations among all the variables in the study. Most notably, and as expected, anomalizing and proactive leader sensemaking were highly correlated $(r=.55)$. However, the exploratory factor analysis suggests that these are actually distinct constructs. In addition, we also examined variance inflation factors and found that they were all less than 2.5 further suggesting that multicollinearity is not a problem (Chatterjee \& Price, 1991).

We tested our hypotheses using hierarchical ordinary least squares regression (see Table 2). We first entered the control variables and found that crews with higher levels of familiarity with each other $(\beta=.06$, $p<.001)$ and greater goal clarity $(\beta=.43, p<.001)$ were associated with more positive assessments of performance. We also found that supervisors $(\beta=-.15$, $p<.01)$ and firefighters on the ground $(\beta=-.21$, $p<.05$ ) assessed performance less positively than commanders, a finding consistent with other research suggesting that top leaders in contrast to frontline workers often have a more positive view of performance. The regressions analyses provide support for Hypothesis 1. Anomalizing was positively associated with performance when entered alone $(\beta=.17, p<.001$, model 2$)$ or with proactive leader sensemaking $(\beta=.09, p<.05$, model 4). Supporting Hypothesis 2 , we found that proactive leader sensemaking was positively associated with performance when entered alone $(\beta=.20$, $p<.001$, model 3$)$ or with anomalizing $(\beta=.16, p<.001$, model 4). Taken together, this constitutes strong support for our hypotheses and provides evidence for specific behaviours of crew members and leaders consistent with those espoused by HROs contributing to performance across different types of fires.

In our theorizing about the three internal sources of uncertainty (goal clarity, group familiarity and task

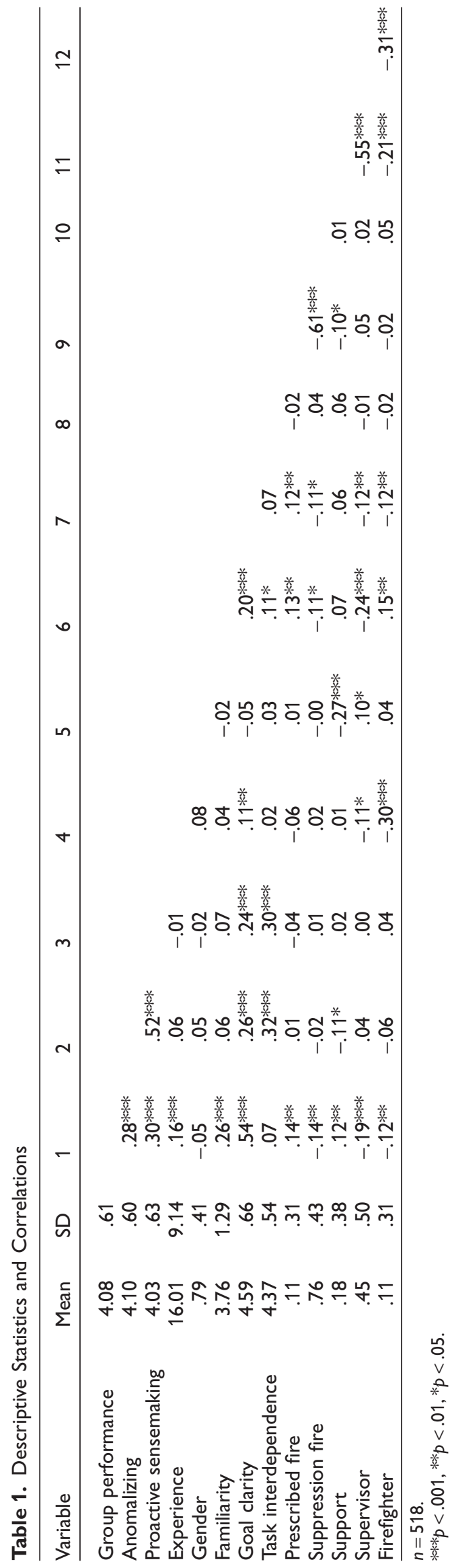


Table 2. Ordinary Least Squares Regression of Group Performance

\begin{tabular}{|c|c|c|c|c|}
\hline & Model 1 & Model 2 & Model 3 & Model 4 \\
\hline Experience & $\begin{array}{c}.06 \\
(.04)\end{array}$ & $\begin{array}{c}.06 \\
(.04)\end{array}$ & $\begin{array}{l}.06 \\
(.04)\end{array}$ & $\begin{array}{c}.06 \\
(.04)\end{array}$ \\
\hline Gender & $\begin{array}{c}-.02 \\
(.06)\end{array}$ & $\begin{array}{c}-.02 \\
(.06)\end{array}$ & $\begin{array}{c}-.01 \\
(.06)\end{array}$ & $\begin{array}{c}-.02 \\
(.06)\end{array}$ \\
\hline Familiarity & $\begin{array}{l}.06^{* * *} \\
(.02)\end{array}$ & $\begin{array}{l}.06 * * * \\
(.02)\end{array}$ & $\begin{array}{l}.06^{* * * *} \\
(.02)\end{array}$ & $\begin{array}{l}.06 \text { **** } \\
(.02)\end{array}$ \\
\hline Goal clarity & $\begin{array}{l}.43 * * * \\
(.04)\end{array}$ & $\begin{array}{l}.39 \text { *** } \\
(.04)\end{array}$ & $\begin{array}{l}.38^{* * * *} \\
(.04)\end{array}$ & $\begin{array}{l}.37^{* * * *} \\
(.04)\end{array}$ \\
\hline Task interdependence & $\begin{array}{c}.02 \\
(.04)\end{array}$ & $\begin{array}{c}-.03 \\
(.04)\end{array}$ & $\begin{array}{c}-.04 \\
(.04)\end{array}$ & $\begin{array}{c}-.06 \\
(.04)\end{array}$ \\
\hline Prescribed fire & $\begin{array}{l}.11 \\
(.09)\end{array}$ & $\begin{array}{l}.12 \\
(.09)\end{array}$ & $\begin{array}{l}.14 \\
(.09)\end{array}$ & $\begin{array}{l}.14 \\
(.09)\end{array}$ \\
\hline Suppression fire & $\begin{array}{c}-.05 \\
(.07)\end{array}$ & $\begin{array}{c}-.05 \\
(.06)\end{array}$ & $\begin{array}{l}-.05 \\
(.06)\end{array}$ & $\begin{array}{c}-.04 \\
(.06)\end{array}$ \\
\hline Supervisor & $\begin{array}{c}-.13^{*} \\
(.06)\end{array}$ & $\begin{array}{c}-.13^{*} \\
(.07)\end{array}$ & $\begin{array}{c}-.16 * * \\
(.06)\end{array}$ & $\begin{array}{l}-.15^{* *} \\
(.06)\end{array}$ \\
\hline Firefighter & $\begin{array}{c}-.18^{*} \\
(.07)\end{array}$ & $\begin{array}{c}-.17 \\
(.09)\end{array}$ & $\begin{array}{c}-.23^{* *} \\
(.09)\end{array}$ & $\begin{array}{c}-.21^{*} \\
(.09)\end{array}$ \\
\hline Support & $\begin{array}{c}.04 \\
(.07)\end{array}$ & $\begin{array}{l}.08 \\
(.07)\end{array}$ & $\begin{array}{l}.03 \\
(.07)\end{array}$ & $\begin{array}{l}.06 \\
(.07)\end{array}$ \\
\hline Anomalizing & & $\begin{array}{l}.17^{* * *} \\
(.04)\end{array}$ & & $\begin{array}{l}.09 * \\
(.04)\end{array}$ \\
\hline Proactive sensemaking & & & $\begin{array}{l}.20 \text { **** } \\
(.04)\end{array}$ & $\begin{array}{l}.16^{* * * *} \\
(.04)\end{array}$ \\
\hline Constant & $\begin{array}{l}1.72^{* * *} \\
(.27)\end{array}$ & $\begin{array}{l}1.44^{* * * *} \\
(.27)\end{array}$ & $\begin{array}{l}1.42^{\text {**** }} \\
(.26)\end{array}$ & $\begin{array}{l}1.33^{* * * *} \\
(.27)\end{array}$ \\
\hline$F$ & $26.43^{* * * *}$ & $26.41^{* * * *}$ & $28.00 * * *$ & $26.18^{* * * *}$ \\
\hline$R^{2}$ & .33 & .35 & .36 & .37 \\
\hline$\Delta R^{2}$ & & .02 & .03 & .04 \\
\hline
\end{tabular}

interdependence), we asserted that the effects would be direct. And as stated above, the findings indeed showed that familiarity and goal clarity positively influence performance. But a question arises as to whether these factors might also play moderating roles. Thus, we conducted post hoc analyses to ascertain the validity of this line of thinking. We found modest support for interaction effects between goal clarity and proactive leader sensemaking $(\beta=-.06, p<.05)$ and goal clarity and anomalizing $(\beta=-.08, p<.05)$. In both cases, goal clarity attenuated the relationships between proactive leader sensemaking, anomalizing and performance. To further investigate the significant interaction effects, we followed Aiken and West (1991) and plotted the significant interactions at $+/-S D$. The relationships between proactive leader sensemaking and group performance and anomalizing and group performance are stronger when goal clarity is low. This suggests that proactive leader sensemaking and anomalizing may be especially critical to performance when goal clarity is low. However, this conclusion should be taken with great caution as the magnitude of the interaction effects on group performance was extremely small. We found no support for other interactions with familiarity and task interdependence.

\section{Discussion}

Almost 50 years ago, C. West Churchman voiced a sentiment in the preface to The Systems Approach (1968, p. xi), which remains relevant both theoretically as well as practically. 'The systems in which we live are far too complicated as yet for our intellectual powers and technology to understand.' If we take seriously Churchman's sentiments, that people and organizations live and act in complex, volatile, uncertain and ambiguous situations, which they cannot or do not understand perfectly (Winner, 1975, p. 69), understanding what enables capabilities for reliable performance under uncertainty is critical. Our findings show that within the firefighting contexts studied here, dual sets of behaviors enacted by leaders and frontline workers are integral to effective performance under uncertainty. Controlling for goal clarity and group familiarity, higher performance occurred when leaders and firefighters on the frontline deeply engaged in their contexts and directed their 
behaviours towards proactively searching for and making sense of potential trouble spots.

The findings contribute to the literature in several ways. First, and perhaps most importantly, our findings provide strong support for the importance of particular leadership behaviours in enabling performance under trying conditions. Although there exist myriad case studies showing the criticality of leader behaviours in enabling reliable performance in dynamic conditions (e.g., Bigley et al., 2001; Klein et al., 2006), large-sample quantitative studies are rare. Similarly, few studies have directly examined the micro-behaviours by which frontline employees surface discrepant cues (see Barton et al., 2009; Christianson et al., 2009; Gittell, 2002 for notable exceptions).

Second, and relatedly, the findings reaffirm the importance of active sensemaking processes - both to becoming aware of details, and also to understanding what those details mean. The dangers of normalizing (and conversely the benefits of anomalizing) have taken centre stage since Vaughan's (1996) reanalysis of the 1986 Challenger space shuttle disaster. But to our knowledge, these ideas have received little further empirical scrutiny. Indeed, our findings show the benefits of proactively seeking to become alert to details and avoiding oversimplifying them into familiar events. Moreover, the act of looking for anomalies may actually serve to trigger sensemaking (anomalizing and sensemaking are positively associated). Anomalies provide informational value (e.g., this part of the system may be failing), and they also create an occasion for sensemaking (Jett \& George, 2003; Weick, 1995). This represents a rethinking of sensemaking as we find evidence that the discrepancies triggering further sensemaking are not external events, but rather often created by organizational actors as a means of effectively navigating an uncertain context.

Third, our findings illustrate how organizations can create a break in the momentum of action - momentum, which otherwise may prevent renewed sensemaking. This suggests that the very act of looking for anomalies may be critical to the management of uncertainty - not just because it provides important information - but because the act of looking disrupts the momentum of ongoing events, triggers doubt and motivates renewed efforts to make sense. Initial sensing processes are important, but a growing stream of work suggests that organizations and their members often fail to effectively manage unexpected surprises (recognize and readjust or reorient in dynamic situations) because the uninterrupted momentum of previous decisions and ongoing actions hinders sensemaking (Barton et al., 2009). Critically, if conditions change but sensemaking is not renewed, interpretations of the emerging situation are not updated and organizations are apt to remain embedded in ineffective or inappropriate frameworks.
As a result, they are ill-equipped to adjust and respond to changing conditions.

Finally, our findings suggest some of the microprocesses that likely underlie organizational resilience. Resilience refers to the 'ability to absorb strain and preserve (or improve) functioning despite the presence of adversity ... [and] to recover or bounce back from untoward events' (Sutcliffe \& Vogus, 2003, p. 96). Enacting resilience involves engaging with the reality of difficult situations and actively searching for and reporting errors or other unexpected problems (Watts-Perotti \& Woods, 2009; Weick et al., 2007) rather than avoiding or merely surviving adversity. Resilience also entails cultivating and using resources (e.g., emotional, social, technical, capital) flexibly to enact new, adaptive responses (Caza \& Milton, 2011; Coutu, 2002; Fredrickson, Tugade, Waugh, \& Larkin, 2003; Kahn, Barton, \& Fellows, 2013; Powley, 2009; Rerup, 2001). Moreover, research suggests leaders can play an important role in creating a context for organizational resilience (Beck \& Plowman, 2009; Duhigg, 2012; Rajah \& Arvey, 2013). Organizations that face a constantly uncertain and dynamic environment (like wildland firefighting and HROs) cannot rely solely on strategies aimed at reducing uncertainty. Rather, they must perform reliably despite uncertainty. Our research suggests specific practices through which organizations proactively engage with difficult situations (rather than avoid them entirely), integrate the reality of what is happening (rather than hoping for the best) and respond in flexible, adaptive ways.

Our findings should be considered in light of three limitations. First, our data are cross-sectional so we cannot ascertain the causality of our arguments. Future research should use longitudinal designs to verify the causal nature of our arguments. Second, our performance outcome comes from the same source as the independent variables. To ensure a large sample of firefighters and fires, we needed to use a key informant design and a perceptual measure of performance. A key informant design should minimize risks of common method bias because the informant is reporting on collective rather than their own performance (minimizing social desirability pressures) and prior research suggests that perceptual measures of performance are consistent with more objective measures in such circumstances (Glick et al., 1990). But future research could validate our findings using different measures of performance. Lastly, firefighting is a very unique uncertain, ambiguous context, and it is unclear whether the results would hold up in other settings. However, our theorizing, as well as prior work on HROs (Weick et al., 1999), suggests that processes of anomalizing and proactive leader sensemaking should generalize to contexts characterized by high levels of uncertainty and ambiguity. Still, we encourage other researchers to 
further examine anomalizing and proactive leader sensemaking in other contexts.

In this study, we have theorized and tested two novel micro-level processes that enable rapid and ongoing sensemaking under conditions of uncertainty. We find that anomalizing and proactive leader sensemaking play crucial roles in determining success of wildland firefighting teams. We hope that it inspires further examination of these two constructs and investigation of this important context.

\section{Acknowledgements}

The authors would like to thank Anne Black, Deirdre Dether, Paula Nasiatka and David Thomas as well as the Wildland Fire Lessons Learned Center and the Aldo Leopold Wilderness Research Institute for their instrumental help in acquiring data for this study and for their valuable insight into the fire community. The authors are grateful to the Ross School of Business, University of Michigan for the financial sponsorship of this study.

\section{References}

Aiken, L. and West, S. (1991), Multiple regression:Testing and interpreting interactions, Sage, Newbury Park, CA.

Baron, R.M. and Misovich, S.J. (1999), 'On the Relationship Between Social and Cognitive Modes of Organization', in Chaiken, S. and Trope, Y. (eds), Dual Process Theories in Social Psychology, The Guilford Press, New York, Pp. 586-605.

Barton, M.A. and Sutcliffe, K.M. (2009), 'Overcoming Dysfunctional Momentum: Organizational Safety as a Social Achievement', Human Relations, Volume 62 , Number 9, pp. 1327-1356.

Beck, T.E. and Plowman, D.A. (2009), 'Experiencing Rare and Unusual Events Richly: The Role of Middle Managers in Animating and Guiding Organizational Interpretation', Organization Science, Volume 20, Number 5, pp. 909-924.

Bigley, G.A. and Roberts, K.H. (2001), 'The Incident Command System: HighReliability Organizing for Complex and Volatile Task Environments', Academy of Management Journal. Academy of Management, Volume 44, Number 6, Pp. 1281-1300.

Blatt, R., Christianson, M.K., Sutcliffe, K.M. and Rosenthal, M.M. (2006), 'A Sensemaking Lens on Reliability', Journal of Organizational Behavior, Volume 27, Number 7, pp. 897-917.

Burns, T. and Stalker, G.M. (1961), The Management of Innovation, Tavistock Publications, London.

Caza, B.B. and Milton, L.P. (2011), 'Resilience at Work: Building Capability in the Face of Adversity', in Spreitzer, G. and Cameron, K. (eds), The Oxford Handbook of Positive Organizational Scholarship, Oxford University Press, Oxford, pp. 895-908.

Chatterjee, S. and Price, B. (1991), Regression Analysis by Example (2nd edn), John Wiley \& Sons, New York.

Christianson, M.K., Farkas, M.T., Sutcliffe, K.M. and Weick, K.E. (2009), 'Learning Through Rare Events: Significant Interruptions at the Baltimore \& Ohio Railroad Museum', Organization Science, Volume 20, Number 5, pp. 846-860.

Churchman, C.W. (1968), The Systems Approach, Dell New York, New York.

Coutu, D.L. (2002), 'How Resilience Works', Harvard Business Review, Volume 80, Number 5, pp. 46-50.

Duhigg, C. (2012), The Power of Habit: Why We Do What We do in Life and Business, Doubleday, Canada.

Faraj, S. and Sproull, L. (2000),'Coordinating Expertise in Software Development Teams', Management Science, Volume 46, Number 12, pp. 1554-1568.

Faraj, S. and Xiao, Y. (2006), 'Coordination in Fast Response Organizations', Management Science, Volume 52, Number 8, pp. 1155-1169.

Fredrickson, B.L., Tugade, M.M., Waugh, C.E. and Larkin, G.R. (2003), 'What Good are Positive Emotions in Crises? A Prospective Study of Resilience and
Emotions Following the Terrorist Attacks on the United States on September 11 th, 2001', Journal of Personality and Social Psychology, Volume 84, Number 2, Pp. $365-376$.

Gittell, J.H. (2002), 'Coordinating Mechanisms in Care Provider Groups: Relational Coordination as a Mediator and Input Uncertainty as a Moderator of Performance Effects', Management Science, Volume 48, Number 11, pp. 1408 1426.

Glick, W.H., Huber, G.P., Miller, C.C., Doty, D.H. and Sutcliffe, K.M. (1990), 'Studying Changes in Organizational Design and Effectiveness: Retrospective Event Histories and Periodic Assessments', Organization Science, Volume 1, Number 3, pp. 293-312.

Goodman, P.S. and Leyden, D.P. (1991), 'Familiarity and Group Productivity', Journal of Applied Psychology, Volume 73, pp. 81-86.

Jett, Q.R. and George,J.M. (2003), 'Work Interrupted:A Closer Look at the Role of Interruptions in Organizational Life', Academy of Management Review. Academy of Management, Volume 28, Number 3, pp. 494-507.

Kahn, W.A., Barton, M.A. and Fellows, S. (2013), 'Organizational Crises and the Disturbance of Relational Systems', Academy Of Management Review. Academy of Management, Volume 38, Number 3, pp. 377-396.

Klein, G., Pliske, R., Crandall, B. and Woods, D.D. (2005), 'Problem Detection', Cognition, Technology and Work, Volume 7, Number 1, pp. 14-28.

Klein, K.J., Ziegert, J.C., Knight, A.P. and Xiao, Y. (2006), 'Dynamic Delegation: Shared, Hierarchical, and Deindividualized Leadership in Extreme Action Teams', Administrative Science Quarterly, Volume 51, Number 4, pp. 590 621.

Lipshitz, R. and Strauss, O. (1997), 'Coping with Uncertainty: A Naturalistic Decision-Making Analysis', Organizational Behavior and Human Decision Processes, Volume 69, Number 2, pp. 149-163.

Locke, E.A., Saari, L.M., Shaw, K.N. and Latham, G.P. (1981), 'Goal Setting and Task Performance: 1969-1980', Psychological Bulletin, Volume 90, Number 1, pp. 125-152.

Madsen, P.M., Desai, V.M., Roberts, K.H. and Wong, D. (2006), 'Mitigating Hazards Through Continuing Design:The Birth and Evolution of a Pediatric Intensive Care Unit', Organization Science, Volume 17, Number 2, pp. 239-248.

Murphy, P.R. and Jackson, S.E. (1999), 'Managing Work-Role Performance: Challenges for 21st Century Organizations and Employees', in Ilgen, D.R. and Pulakos, E.D. (eds), The Changing Nature of Work Performance, Jossey-Bass, San Francisco, pp. 325-365.

Perin, C. (2005), Shouldering Risks: The Culture of Control in the Nuclear Power Industry, Princeton University Press, Princeton, NJ.

Perrow, C. (1967), 'A Framework for the Comparative Analysis of Organizations', American Sociological Review, Volume 32, Number 2, pp. 194 208.

Powley, E.H. (2009),'Reclaiming resilience and safety: Resilience activation in the critical period of crisis', Human Relations, Volume 62, Number 9, pp. 12891326.

Rajah, R. and Arvey, R. (2013), 'Helping Group Members Develop Resilience', in DuBrin, A.J. (ed.), Handbook of Research on Crisis Leadership in Organizations, Edward Elgar Publishing, Incorporated, pp. 149-173.

Rerup, C. (2001), ' 'Houston, We Have a Problem': Anticipation and Improvisation as Sources of Organizational Resilience', Comportamento Organizational E Gestao,Volume 7, Number 1, pp. 21-44.

Rerup, C. (2009), 'Attentional Triangulation: Learning from Unexpected Rare Crises', Organization Science, Volume 20, Number 5, pp. 876-893.

Roberts, K.H. (1990), 'Some Characteristics of High-Reliability Organizations', Organization Science, Volume 1, pp. 160-177.

Roberts, K.H., Madsen, P.M., Desai, V.M. and Van Stralen, D. (2005), 'A Case of the Birth and Death of a High Reliability Healthcare Organization', Quality and Safety in Health Care, Volume 14, pp. 216-220.

Roe, E. and Schulman, P.R. (2008), High Reliability Management: Operating on the Edge, Stanford University Press, Palo Alto, CA.

Rulke, D.L. and Galaskiewicz, J. (2000), 'Distribution of Knowledge, Group Network Structure, and Group Performance', Management Science, Volume 46, Number 5, pp. 612-625.

Schulman, P.R. (2004), 'General Attributes of Safe Organizations', Quality and Safety in Health Care, Volume 13, Number 1, pp. 39-44.

Starbuck, W.H. and Farjoun, M. (2005), Organization at the Limit: Lessons from the Columbia Disaster, Blackwell, New York.

Sutcliffe, K.L. and Vogus, T. (2003), 'Organizing for Resilience', in Cameron, K., Dutton, J.E. and Quinn, R.E. (eds), Positive Organizational Scholarship, BerrettKoehler, San Francisco.

Sutcliffe, K.M. and Christianson, M.K. (2011), 'Managing the Unexpected', in Cameron, K. and Spreitzer, G. (eds), Handbook of Positive Organizational Scholarship, Oxford University Press, Oxford, UK, pp. 843-855. 
Sutcliffe, K.M. and Weick, K.E. (2008), 'Information Overload Revisited', in Starbuck, W.H. and Hodgkinson, G. (eds), Handbook of Organizational Decision Making, Oxford University Press, Oxford, UK, pp. 56-75.

Thompson, J.D. (1967), Organizations in Action, McGraw Hill, New York.

Turner, B. (1976), 'The Organizational and Interorganizational Development of Disasters', Administrative Science Quarterly, Volume 21, Number 3, pp. 378-397.

Vaughan, D. (1996), The Challenger Launch Decision, University of Chicago Press, Chicago.

Vogus, T.J. and Sutcliffe, K.M. (2007a), 'The Safety Organizing Scale: Development and Validation of a Behavioral Measure of Safety Culture in Hospital Nursing Units', Medical Care, Volume 45, Number 1, pp. 46-54.

Vogus, T.J. and Sutcliffe, K.M. (2007b), 'The Impact of Safety Organizing, Trusted Leadership, and Care Pathways on Reported Medication Errors in Hospital Nursing Units', Medical Care, Volume 45, Number 10, pp. 997-1002.

Vogus, T.J. and Welbourne, T.M. (2003), 'Structuring for High Reliability: HR Practices and Mindful Processes in Reliability-Seeking Organizations', Journal of Organizational Behavior, Volume 24, pp. 877-903.

Watts-Perotti, J. and Woods, D.D. (2009), 'Cooperative Advocacy: An Approach for Integrating Diverse Perspectives in Anomaly Response', Computer Supported Cooperative Work-the Journal of Collaborative Computing, Volume 18, Number 2-3, pp. 175-198.

Weick, K. (2001), Making Sense of the Organization, Blackwell Publishing, Malden, MA.

Weick, K.E. (1993), 'The Collapse of Sensemaking in Organizations: The Mann Gulch Disaster', Administrative Science Quarterly, Volume 38, Number 4, Pp. 628-652.

Weick, K.E. (1995), 'South Canyon Revisited: Lessons from High Reliability Organizations', Wildfire, Volume 4, pp. 54-68.

Weick, K.E. (2011), 'Organizing for Transient Reliability: The Production of Dynamic Non-Events', Journal of Contingencies and Crisis Management, Volume 19, Number 1, pp. 21-27.

Weick, K.E. and Sutcliffe, K.M. (2006), 'Mindfulness and the Quality of Organizational Attention', Organization Science, Volume 16, Number 4, Pp. 409-421.

Weick, K.E. and Sutcliffe, K.M. (2007), Managing the Unexpected (2nd edn), Jossey-Bass, San Francisco.

Weick, K.E., Sutcliffe, K.M. and Obstfeld, D. (1999), 'Organizing for High Reliability: Processes of Collective Mindfulness', in Staw, B.M. and Cummings, L.L. (eds), Research in Organizational Behavior, Vol. 21, JAI Press, Inc, Greenwich, CT, pp. 81-123.

Winner, L. (1975). 'Complexity and the Limits of Human Understanding', in LaPorte, T. (ed.), Organized Social Complexity: Challenge to Politics and Policy. Princeton University Press, Princeton.

\section{Appendix A}

\section{Anomalizing}

(1) We actively looked for instances of small things going wrong to try to learn what was happening.

(2) People were rewarded or thanked for spotting potential trouble spots.

(3) We were encouraged to express differing points of view.

(4) We assessed each situation on its own rather than assuming it would be similar to other situations we'd experienced.

(5) When members had different opinions, we tried to understand one another's views.

\section{Proactive leader sensemaking}

(1) My boss actively sought input from a broad range of folks when making decisions.

(2) My boss actively encouraged subordinates to question decisions that didn't make sense to them.

(3) My boss encouraged people to bring up potential problems.

(4) My boss listened to the less experienced members of my group when they brought up ideas or issues

(5) My boss actively listened when different views were presented.

(6) My boss rejected or ignored input from others.

(7) My boss told us to pay attention to one another's input or ideas.

(8) My boss told us that our task required us to work well together. 